\title{
Diets, Nutrition and Poverty: The Indian Experience ${ }^{1}$
}

\author{
Raghav Gaiha $^{\mathrm{a}}$, Raghbendra Jha ${ }^{\mathrm{b}}$, and Vani S. Kulkarni ${ }^{\mathrm{c}}$
}

\begin{abstract}
This chapter focuses on the Indian experience with dietary changes, their nutritional implications, and policy response to alleviate nutritional deprivation. We review the evidence on nutrient intake and dietary changes, particularly the downward shift in calorie, protein and other nutrient intake over the period 1993-2004 and provide a demand based explanation of this shift. We report on eating out as an aspect of dietary transition, examine the relationship between calorie deprivation and poverty, and argue against delinking of the two. We analyse poverty nutrition traps, whether child undernutrition is underestimated and the double burden of undernutrition and obesity. We examine the (potential) contribution of National Rural Guarantee Scheme and Public Distribution System in mitigating the extent and severity of undernutrition. We emphasize that food security entails a right to certain policies to ensure food entitlements, as opposed to a narrow interpretation of the right to food in terms of state provisioning of these entitlements. Conclusions from a broad policy perspective are delineated.
\end{abstract}

JEL Classification Code: C21, D12, I31, I 32.

Keywords: Diet, Nutrition, Engel Curves, India.

${ }^{\text {a. }}$ Faculty of Management Studies, University of Delhi;

b. ASARC, Arndt-Corden Department of Economics, Australian National University;

c. Department of Sociology, Yale University.

\footnotetext{
${ }^{1}$ Much of the research summarised here was conducted by the first author during his stay at the Department of Urban Studies, MIT, in close collaboration with the co-authors. He would like to thank Bish Sanyal for his support and encouragement. We are grateful to Anil Deolalikar for valuable advice throughout this study, and to L. Haddad and Kenneth Hill for useful discussions in the initial stage. Sonal Desai was most helpful in acquainting us with the use of the India Human Development Survey, which she had designed and conducted jointly with the National Council of Applied Economic Research. Raj Bhatia carried out the statistical analysis with great efficiency. Last but not the least, we are grateful to Ron Herring for the invitation to contribute to the Handbook on Food, Politics and Society, Oxford University Press. Any errors are our sole responsibility.
} 


\section{Introduction}

India is currently undergoing rapid economic and demographic transformation. Since 1980, average living standards have experienced a sustained and rapid rise. Gross domestic product per capita has risen by a trend rate of $4 \%$ annually. Poverty declined at an annual rate of $0.88 \%$ during $1983-94$, and at $0.77 \%$ during $1993-05$. Life expectancy rose from 54 years to 69 years while the (crude) birth rate fell from 34 to 22 between 1980-2008. Between 19802000 the share of the urban population rose from 23 to 28 percent. By 2030, it is likely to be $41 \%$.

A key feature of the economic transformation has been the change in the nature of the Indian diet. As Indian and global markets integrate and communication improves, diet transitions become unavoidable resulting in a move away from inferior to superior foods and a substitution of traditional staples by primary food products that are more prevalent in western diets. These shifts are reflected in higher consumption of proteins, sugars, fats and vegetables. Some of the underlying factors behind this dietary transition are expansion of the middle class, higher female participation in labour markets, emergence of nuclear two-income families, a sharp age divide in food preferences (with younger age groups more susceptible to new foods advertised in the media), and rapid growth of supermarkets and fast-food outlets.

FAOSTAT reveals some significant dietary changes. In the 1980s, these included

(i) A sharp rise in consumption of both animal and vegetable products.

(ii) The consumption of milk has the largest proportional increase among animal products.

(iii) Rice, pulses, wheat, spices, and oils constitute the largest increases among vegetable products. $^{2}$

During the 1990s, significant changes in the pattern of food consumption included:

(i) A marked increase in the consumption of animal products (especially animal fats), a relatively modest increase in consumption of vegetable products.

\footnotetext{
${ }^{2}$ We follow a more disaggregated classification of vegetables in our analysis with NSS household data for 1993 and 2004.
} 
(ii) Among vegetable products, a large increase in the consumption of wheat, starchy roots, vegetable oils, sugar and sweeteners, and fruits (while that of rice, pulses and other cereals declined).

(iii) Among starchy roots, a sharp increase in potato consumption, given its predominance in energy-dense food products (e.g. fries and potato chips).

(iv) A change in the use of wheat due to a move away from the traditional chapatti to more commercialized and westernized bread products. ${ }^{3}$

The health implications of the dietary transition are unclear. A more varied and nutritionally balanced diet and higher levels of food hygiene are associated with better health. But there is a trade-off as more energy-dense foods are linked to higher incidence of diet-related noncommunicable diseases (NCDs) such as diabetes, coronary heart disease and certain types of cancer. Although India lags behind other developing countries in the epidemiological transition - decline in infectious disease mortality compensated increasingly by higher mortality from chronic degenerative NCDs - there is some evidence of this transition taking place. Estimated deaths from NCDs are projected to rise from 3.78 million in 1990 (40.46\% of all deaths) to 7.63 million in 2020 (66.70\% of all deaths). Worse, about a quarter of the deaths occurred in the 35-64 age group in urban areas (Kulkarni and Gaiha, 2010).

\section{Scheme}

This chapter focuses on dietary changes, their nutritional implications, and policy response to alleviate nutritional deprivation. Sections II and III review the evidence on nutrient intake and dietary changes, focusing particularly on the downward shift in calorie, protein and other nutrient intake over the period 1993-2004. Section IV undertakes a demand based explanation of the factors driving the downward shifts. In section $\mathrm{V}$ recent evidence on eating out as an aspect of dietary transition in India is reviewed. Section VI examines the relationship between calorie deprivation and poverty, and argues against delinking of the two. Sections VII, VIII and IX, respectively, focus on poverty nutrition traps, a determination of whether child undernutrition is underestimated and the double burden of undernutrition and obesity. Section X examines the (potential) contribution of National Rural Employment Guarantee Scheme (NREG) and Public Distribution System (PDS) in mitigating the extent and severity of undernutrition (including micronutrient deficiency). As current debates on

\footnotetext{
${ }^{3}$ For details, see Pingali and Khwaja (2004).
} 
food security have veered towards a right to food, a new perspective is delineated, in section $\mathrm{XI}$, to suggest that food security involves a right to policies (or a 'right to a right') designed to ensure fulfillment of food entitlements. Finally, section XII makes some concluding observations from a broad policy perspective.

\section{Nutrient Intake}

\section{(a) The Puzzle}

Various sources - including detailed household consumption expenditure surveys conducted by the National Sample Survey Organisation (NSSO) every five years in India (the so-called thick samples) — point to a puzzle. Despite rising incomes, there has been sustained decline in per capita nutrient intake. In an important contribution, Deaton and Dreze (2009) (henceforth DD) offer an analysis of the decline in nutrient intake over the period 1983 to 2004. Their principal findings are:

(i) Average calorie consumption was about 10\% lower in rural areas in 2004-05 than in 1983. The proportionate decline was larger among the more affluent sections of the population, and negligible for the bottom quartile of the per capita expenditure scale. In urban areas, there was a slight change in average calorie intake over this period.

(ii) Proteins and other nutrients also experienced a drop in per capita consumption, whereas that of fat has increased in both rural and urban areas.

(iii) As incomes rose over this period, these declines are puzzling. A contentious view offered by DD is that the declines are not attributable to changes in relative prices as an aggregate measure of the price of food - treated synonymous with the price of calories - changed little during this period. So the puzzle boils down to this: per capita calorie consumption is lower at a given level of per capita household expenditure, across the expenditure scale, at low levels of per capita expenditure as well as high, i.e., there is steady downward shift of the calorie Engel curve. ${ }^{4}$

(iv)DD are emphatic that the downward shift of the calorie Engel curve is due to lower calorie 'requirements', associated mainly with better health and lower activity levels. As the evidence offered is fragmentary and patchy, but not implausible, this explanation is largely conjectural. Specifically, they draw attention to major

\footnotetext{
${ }^{4}$ This curve denotes a relationship between calorie intake and income proxied by expenditure.
} 
expansions in availability of safe drinking water, vaccination rates, transport facilities, and ownership of various effort-saving durables. Relying on evidence furnished by the Indian Council of Medical Research (1990) on a sharp rise in calorie requirements following modest increase in activity levels, they claim that the $10 \%$ reduction in calorie consumption was in part due to lower activity levels associated with ease of obtaining drinking water, extensive use of bicycles and motor bikes and improved public transportation, among others.

This chapter throws more light on the decline in calorie, protein and fat intake and the explanations offered over a shorter period (i.e. 1993-2004). The analysis is based mostly on unit record data collected for the 50th and $61^{\text {st }}$ rounds of the NSS (corresponding to 1993-94 and 2004-05, respectively).

\section{(b) Changes in Calorie, Protein and Fat Intake}

\section{Calories}

Until recently, a calorie intake of 2400 per day was considered adequate for a typical adult engaged in physically strenuous work of a certain duration in rural India. More recent assessments have used lower calorie 'requirements' (1800 calories). ${ }^{5}$

\section{Table 1}

Using the higher calorie requirement of 2400 , over $71 \%$ of the rural households were calorie deprived or more generally undernourished in 1993 (Table 1). ${ }^{6}$ With the lower norm of 1800, this proportion falls sharply to about 31\%, implying a large concentration of households in the calorie intake range of $1800-2400$. The proportion of undernourished rises from $71 \%$ to nearly $80 \%$ in 2004 and the proportion below the lower cut-off rose from about 31\% to close to $37 \%$, indicating high levels of calorie deprivation. While the mean calorie intake of those below 1800 rose slightly (from 1491 to 1516), the mean intake of the larger concentration of households in the next higher range (1801-2400) remained about the same.

\section{Table 2}

\footnotetext{
${ }^{5}$ Srinivasan (1992 ) is deeply skeptical of such requirements on the ground that energy expenditure adjusts to intake within a range.

${ }^{6}$ Although calorie deprivation is an aspect of undernutrition, we sometimes use them interchangeably for expositional convenience.
} 
Table 2 reports estimates for urban India. Assuming lower calorie norms of 1700 and 2100 (given less strenuous physical activity in urban areas), about 28\% consumed less than 1700 calories in 1993. About 58\% were below the higher calorie norm of 2100 . Worse, this proportion rises to about 64\% over the period 1993-2004. Although less alarming than the calorie deprivation increase in rural India, it is nevertheless worrying.

\section{Protein}

Following Gopalan et al.(1971), a cut-off of 60 (gms) of protein intake is used. While protein deficiency is in large measure linked to calorie deficiency, we note that well over $57 \%$ of rural households consumed fewer than the required protein intake in 1993. Just under a quarter of the households consumed $<45$ (gms) of protein. Mean intakes were well below the upper limits, implying concentrations of households with relatively low protein intakes. Within both ranges of protein intake, the proportions rose more than moderately (e.g., in the lower range, the proportion of households rose from about $24 \%$ to about $29 \%$ ). However, mean intakes of protein remained unchanged.

\section{Table 3}

Although the share of protein-deficient urban households in urban India rose slightly (from about $62.67 \%$ to about 64\%), the share below the lower cut-off of 45 (gms) rose sharply (from about $25 \%$ to over $29 \%$ ). Mean protein intakes, however, remained unchanged in these ranges.

\section{Table 4}

\section{Fats}

Although a precise range for fat requirements cannot be specified, Gopalan et al. (1971) recommend that a range of $40-60$ (gms) of fat intake is desirable. ${ }^{7}$ Even considering the first three ranges of fat intake, an astonishingly high estimate for fat deficient households for rural India (over 85\%) is obtained for 1993. Well over one-third of households are under the lowest range of $<20$ (gms). The corresponding household share with fat intakes $<50$ gms fell

\footnotetext{
${ }^{7}$ Gopalan et al. (1971) observe: 'The quantity of fat that should be included in a well balanced diet is not known with any degree of certainty. However, it appears desirable in the present state of knowledge that the daily intake of fat should be such that it contributes no more than 15 to $20 \%$ of the calories in the diet. A total of about 40 to 60 gms of fat can therefore be safely consumed daily, and in order to obtain the necessary amounts of essential fatty acids, the fat intake should include at least 15 gms. of vegetable oils' (pg. 8)
} 
but slightly (to over 83\%). However, the share of households consuming $<20$ gms of fat fell sharply (from over 34\% to well over 22\%). Mean fat intakes remained unchanged.

\section{Table 5}

Using higher ranges of fat intake for urban areas, fat deprivation was pervasive (about $81 \%$ of the households consumed $<60$ gms of fats in 1993). About a quarter consumed $<25$ gms. Over the period 1993-2004, the reduction in the proportion of fat-deprived was slight (from $81 \%$ to $78 \%$ ). However, as in rural India, the proportion consuming fats $<25$ gms fell sharply. However, those consuming fats in the range 41-60 gms rose more than moderately. Changes in mean fat intake were negligible.

\section{Table 6}

Thus, taking nutritional norms as valid, the overall picture of nutritional deprivation worsened considerably over the period 1993-2004.

\section{(c) Engel Curves}

\section{Calories}

DD drew attention to the downward shift in the calorie Engel curve over the period 19832004. We find that for the period 1993-2004 the calorie Engel curves for rural India display a downward shift — especially above extremely low levels of monthly per capita expenditure (MPCE) at 2004 prices. The calorie Engel curve for 2004 crosses over the 1993 curve at (approximately) Rs 150, implying slightly higher calorie intake at lower MPCE in 2004. At higher MPCE, there is a reversal with fewer calories consumed. The proportionate reduction in calorie intake is much higher at higher MPCE in 2004.

\section{Figure 1}

The calorie Engel curve in urban India for 2004 lies above that for 1993 up to MPCE of (slightly over) Rs 500 and then below it. Thus, at MPCE <Rs 500, calorie intake was higher and, above it, lower in 2004. The proportionate reduction in calorie intake at higher MPCE was larger.

\section{Figure 2}


Hence, there is evidence of a downward shift of the calorie Engel curve in both rural and urban India over the period 1993-2004.

\section{Protein}

Figures 3 and 4 report protein Engel curves for rural and urban India between 1993-2004. The rural-urban contrast in protein intake is striking. In the rural areas, protein intake was consistently lower across expenditure classes in 2004 than in 1993. The gap between 1993 and 2004 intakes widens considerably at higher MPCE. In urban areas, the 2004 curve was above the 1993 curve at low levels of MPCE and, after the cross-over expenditure of about Rs 500, it lies below the 1993 curve.

\section{Figure 3 and 4}

\section{Fats}

The fat Engel curves for rural India in 1993 and 2004 largely overlap except at higher MPCE. In the urban areas, by contrast, the 2004 curve lay above the 1993 curve over a large part of MPCE, with a narrowing of the gap and convergence at about Rs 900.

\section{Figures 5 and 6}

\section{Changes in Diets and Nutrition}

\section{(i) Rural and Urban Samples}

We build on the DD analysis (2009) of food commodities that contributed to reduction in calories, protein and fats.

\section{Calories}

In 1993 (2004) cereals ${ }^{8}$ accounted for about 71\% (67.5\%) of total calorie intake. Calories from cereals recorded a significant reduction (from 1530 calories to 1383 calories), i.e., 9.6\%. Out of the three other important sources of calories (milk/milk products/ghee/butter, Vanaspati-oil, pulses/nuts/dry fruits), the contribution of Vanaspati-oil rose considerably (by about 31\%) while that of the remaining two remained largely unchanged. Sugar's contribution fell by about $5 \%$ while that of vegetables rose by $15 \%$. Altogether calorie intake declined from 2156 to 2047, i.e., by about 5.5\%.

\footnotetext{
${ }^{8}$ See Gaiha et al. (2010 a).
} 
In urban India, calorie intake declined from 2074 to 2021, about 2.6\%, much of it due to reduction in cereal calories - from 1213 to 1133 - 6.6\%. Among other calorie sources, milk/milk products/ghee/butter contributed a slightly higher amount (their contribution rose from 181 to 189 - about 4.5\%); there was a substantial increase in calorie intake from vanaspati-oil ( from 168 to 199 - 18.5\%; by contrast, that of sugar decreased — from 129 to 115 - about 11\%); and that of pulses/nuts/dry fruits rose only by a negligible amount.

\section{Protein}

In rural India, protein intake declined — from 60.3 (gms) to 55.8 (gms) — i.e., by about 7.5\%. Much of it reflected a reduction in protein intake from cereals - from 41.8 (gms) to 37.9 (gms), i.e., about 9.3\%. Intake from other sources remained largely unchanged between 1993-2004. By contrast, average protein intake in urban India fell only slightly from 57.3 (gms) to 55.4 (gms), i.e., barely 3.3\%, most of it due to reduction in protein intake from cereals - from 34.1 (gms) to 32 (gms), i.e. over $6 \%$.

\section{Fats}

Between 1993-2004 fat intake rose from 31.5 (gms) to 35.4 (gms) in rural India, i.e. 12. 4\%. There was a slight reduction in fat intake from cereals, the main contributor to the higher intake was Vanaspati-oil — its contribution rose from 12.3 (gms) to 16.2 (gms), i.e., under $32 \%$. Pulses/nuts/dry fruits contributed a slightly higher amount — from 2.4 (gms) to 3.1 (gms).

Urban India also recorded increased intake of fats — from 42.1 (gms) to 47.5 (gms), i.e. just under $13 \%$. As in rural India, much of the increase came from Vanaspati-oil - its contribution rose from 18.6 (gms) to 22.1 (gms), or about 19\%. Additional fat intake due to milk/milk products/ghee/butter was small — it increased from 13.2 (gms) to 13.8 (gms). Contribution of pulses/nuts/dry fruits also rose by a small amount - 4 (gms) to 5.6 (gms).

\section{Changes in Diets}

Underlying these changes in nutrient intakes from different food commodities are the changes in their own consumption (Table 7).

Table 7 
In rural India there was sharp reduction in cereal consumption - from 448 (gms) to 404 (gms) - i.e., of about 10\%. The intake of sugar decreased - from 26 (gms) to 24.7 (gms) — i.e. 5\% . Milk products/ghee/butter recorded a slightly lower intake — from 114. 3 (gms) to 111.8 (gms) - i.e., about 2.2\%. Pulses/nuts/dry fruits recorded a sharp drop — from 366.3 (gms) to 203.5 (gms), i.e. about 44\%. In contrast, intake of Vanaspati-oil rose more than moderately - from 12.3 (gms) to 16.2 (gms), i.e., about 32\%. Intake of eggs, and meat/fish/poultry rose but only slightly. Consumption of fruits, and vegetables rose moderately — from 16.4 (gms) to 19.7 (gms), and from 159.5 (gms) to 167.6 (gms), respectively.

Reduction in cereal intake was lower in urban India, falling from 355 (gms) to 331.3 (gms), about 6.7\%. Pulses/nuts/dry fruits recorded a sharp reduction — from 523.7 (gms) to 327.2 (gms), i.e., about 37.5\%. Sugar also recorded a lower intake — from 32.4 (gms) to 29 (gms), i.e., about $10.50 \%$. Eggs, meat/fish/poultry, and vegetables recorded small increases. While milk/milk products/ghee/butter, and Vanaspati-oil recorded moderately higher intakes rising from 143.2 (gms) to 149.1 (gms), and from 18.6 (gms) to 22.1 (gms), respectively), vegetables recorded more than a moderate increase — from 168 (gms) to 182.4 (gms), i.e. about $8.51 \%$.

Thus food composition/diet changed considerably in both rural and urban areas over the period 1993-2004. ${ }^{9}$ Reduction in cereal intake — the single largest source of calorie and protein intake — ranged from $6.7 \%$ to $9.8 \%$. There were strong reductions in the intake of pulses/nuts/dry fruits. In contrast, intakes of Vanaspati-oil, and vegetables rose. As these are linked to intakes of calories, proteins and fats with varying importance, an investigation of how food consumption patterns changed in response to changes in income and relative prices is necessary.

\section{Demand-Based Explanation of Downward Shift in Calorie Intake}

DD (2009) offer an explanation of the downward shift in nutrient intake. We confine our comments to calories here ${ }^{10}$ and emphasise the roles of food prices, MPCE, and a catch-all time variable, designed to capture the effects of changes in life-styles, activity patterns and

\footnotetext{
${ }^{9}$ For a rich and insightful analysis of dietary changes in India — specifically, the higher fat consumption by the bottom six expenditure per capita deciles over the period 1993-2004 — see Deolalikar (2010).

${ }^{10} \mathrm{~A}$ longer version (Gaiha et al. 2010 a) provides details of a demand-based explanation of changes in other nutrients (protein and fats).
} 
improvements in the epidemiological environment, in explaining shifts in calorie demand between 1993 and 2004. ${ }^{11}$ A distillation of our econometric results, based on state-level data. $^{12}$ follows. As price changes induce substitutions between commodities with differing nutrient content, the price effects include both direct and indirect effects (through substitutions). Hence, 'calorie demand' subsumes changes in consumption of food commodities due to changes in their prices, expenditure and other (unrelated) factors.

Our analysis for rural India shows significant negative price effects of cereals such as rice and wheat on calorie demand. These effects, however, weakened during 1993-2004. Prices of vegetables also affected calorie demand negatively but the effect was larger (in absolute value) over time. Hence, higher food prices lowered calorie demand.

MPCE had a large positive effect on calorie demand - a $1 \%$ increase in per capita expenditure results in a $0.39 \%$ increase in calorie demand. Besides, other factors (health improvements, and less strenuous activity patterns, among others) contributed substantially to reduction in calorie demand, as conjectured by DD. So, while their conjecture is not rejected, it is complementary to our demand-based explanation.

During 1993-2004, while MPCE stagnated, food prices rose sharply (e.g. cereal prices by about 58\%, and vegetables' prices by close to 100\%). Juxtaposing these facts against the food price and expenditure effects, it follows that while stagnation of MPCE left calorie demand unchanged, higher food prices reduced it. Lower calorie requirements, for reasons stated earlier, also contributed to a lower intake in combination with a lower demand.

Why calorie intake fell matters greatly since the policy implications differ vastly. The case for interventions designed to stabilise food prices and expand livelihood opportunities in rural areas is reinforced despite a deafening but misguided chorus that nutritional deprivation is exaggerated or does not matter much.

\footnotetext{
${ }^{11}$ A presumption is that people make informed food choices, based on flavour, packaging, variety and, of course, nutritional content, whence, it is meaningful to talk about calorie, protein and other nutrient demand functions.

${ }^{12}$ For an analysis based on unit record data for 1993 and 2004, see Gaiha et al. (2010 b).
} 


\section{How Pervasive is Eating Out?}

From the perspective of dietary transition as discussed above, we provide a distillation of our findings on eating out, based on an analysis of a nationwide household survey, India Human Development Survey 2005 (IHDS), conducted jointly by the University of Maryland and the National Council of Applied Economic Research. The focus is on the socio-economic status of households eating out, and their spatial distribution. The latter disaggregates household locations into rural and urban areas, urban slums and six metros. ${ }^{13}$.

Eating out is pervasive going by the fact that more than a quarter of the households (about $28 \%$ ) did so. A large majority of those eating out (about 69\%) spent under 99 rupees per month, and about a quarter spent over 200 rupees per month (at 2004-05 prices)..

About 25\% of the Scheduled Castes (SCs), about 27\% of the Scheduled Tribes (STs), and about 31\% each of the Other Backward Castes (OBCs), and others ate out. Even some of the most deprived and socially excluded groups - especially the SCs and STs - have switched from traditional staples to fast foods and opted for greater variety in food consumption. This is further corroborated when the sample is split into the poor and non-poor households using the official poverty line. While a much larger proportion of the non-poor households (about $32 \%$ ) ate out, those among the poor (about 14.50\%) were far from negligible. A more disaggregated classification of the households into four MPCE classes (less than 300 rupees, between 300-500 rupees, between 500-1000 rupees, and greater than 1000 rupees) further dispels any doubts that eating out as a manifestation of dietary transition is mostly a middleclass phenomenon. About 21\% of the households eating out had MPCE below 500 rupees, with the majority (about 79\%) from the lower and upper-middle income classes (i.e., between 500-1000 rupees, and greater than 1000 rupees, with the median expenditure being 633 rupees). Within the low income households too (less than 500 rupees), the share of those eating out was $17 \%$, as opposed to double that among the lower and upper-middle income households.

Interestingly, about two-thirds of the households that ate out were rural, about $31 \%$ were urban, and the remaining (about 3\%) were in urban slums. About 35\% ate out among rural households, about 34\% among urban households, and, surprisingly, about 45\% in urban slums.

\footnotetext{
${ }^{13}$ Gaiha et al. (2010c) provides further details.
} 
In the six largest metros (Mumbai, Delhi, Kolkata, Chennai, Bangalore, and Hyderabad), about $34 \%$ of the households ate out, as compared with about $27 \%$ elsewhere. Over $47 \%$ of the former spent 200 rupees or more per month on eating out, and less than one-quarter of the latter did so. Eating out is thus more pervasive among the metro residents, who also spent larger amounts. A majority of the upper-middle income class households in the metros (about $56 \%$ ) ate out, far in excess of those elsewhere (about 40\%). While more than half of the former spent amounts exceeding 200 rupees per month, about $43 \%$ of the latter did so.

Thus, eating out as a manifestation of dietary transition in India is far more pervasive than a middle-income class urban phenomenon. That this is more typical of large metros is hardly surprising, given the more rapid lifestyle changes, greater exposure to the media, and easier access to eating-out facilities. Dietary changes are also occurring in rural areas and among low-income households in response to growing affluence and the ease of eating out.

\section{Calorie Deprivation and Poverty}

If we go by the number of expert groups constituted in recent years to re-examine the methodology of conducting BPL census and assess poverty, it is tempting to conclude that all is not well with the poor. While official estimates are self-congratulatory in portraying a significant reduction in poverty over the decade 1993-2004 — from about 37\% to over 28\% - as a direct consequence of the liberalisation of the Indian economy and the concomitant growth acceleration, the expert groups are at pains to underplay or steer clear of the implications of a marked decline in calorie intake.

As noted earlier, a somewhat stunning result is that if we go by the norms of per capita calorie norms of 2,100 for urban areas and 2,400 for the rural, the proportions of calorie deficient populations in the urban and rural areas have risen over the period 1993-2004 _ from about $58 \%$ to about $64 \%$ in urban areas, and from about $71 \%$ to about $80 \%$ in rural areas. Hence, at the all-India level, the calorie deficient population rose from about $68 \%$ to about $76 \%$. If these figures tell a story of considerable worsening of nutritional deprivation over a period of comprehensive macro-policy reforms and accelerated growth, it is also a story of abysmal failure of anti-poverty programmes to correct nutritional deprivation and inequity. ${ }^{14}$

\footnotetext{
${ }^{14}$ We do not use calorie deficiency and nutritional deficiency synonymously except to point out that the former is an important aspect of the latter. In fact, prevalence rates of protein, fat and micronutrient deficiencies are high too (Jha et al. 2010).
} 
These comparisons are subject to two caveats: (i) they are based on rigid calorie norms; and (ii) the head-count index of calorie deprivation is sensitive to the calorie norm. As lower calorie norms are recommended by FAO and others, and the head-count index has familiar limitations (e.g. it does not take into account the severity of calorie deprivation), it is worthwhile to supplement this analysis with more flexible comparisons that allow for a wide but permissible range of calorie norms and a class of calorie deprivation indices (i.e. the head-count index, the calorie gap and a distributionally sensitive measure of calorie deprivation assigning higher weights to the most deprived) ${ }^{15}$.

The main findings are summarized below ${ }^{16}$.

(i) In rural India, except for calorie intakes up to 1300, there was worsening of calorie deprivation in terms of all FGT indicators.

(ii) In urban India too, there was worsening of calorie deprivation over a wide range of calorie norms.

(iii) Assessments of protein deprivation in both rural and urban India over the period 1993-2004 are dismal.

(iv)Except for very low fat intake, there was a clear deterioration in rural (as well as urban) India in terms of the FGT class of deprivation indicators.

Thus, there is conclusive evidence of a sharp deterioration in nutritional deprivation over the period 1993-2004.

Notwithstanding this, Datt and Ravallion (2009) produce a dazzling array of statistical evidence to establish that there has been a trend decline in all three FGT class indices of poverty over a period of 50 years, including 15 years of economic reforms. Both urban and rural poverty measures have declined. Comparisons of the pre-reform (until 1991) and postreform periods (up to 2005-06) indicate a faster reduction in the head-count ratio in the latter.

Deaton and Dreze (2010) take issue with Patnaik (2010) on anchoring poverty lines to calorie (nutritional) norms. They argue that there are several reasons for delinking the two, ${ }^{17}$ e.g.,

\footnotetext{
15 These comparisons are based on stochastic dominance tests (Atkinson, 1987). If the cumulative calorie distribution curve, say, for 2004 lies below that for 1993, over the permissible range of calorie norms, it follows that calorie deprivation worsened in terms of the Foster- -Greer- Thorbecke (FGT) class of deprivation indices. These indices include the head-count index, the calorie gap, and a distributionally sensitive index. For a generalisation of the FGT class of poverty indices to undernutrition, see Ravallion (1989).

${ }^{16}$ The interested reader may refer to Gaiha et al. (2010a).
} 
calorie requirements vary between regions, between persons, over time, and so on. Also average calorie intake in India tends to be higher in the poorer, less well-nourished areas. Hence, poverty estimates based on calorie-invariant poverty lines lead to very odd regional patterns, e.g., one of the 'poorest' states, using this method, would be Kerala, because calorie consumption there is very low. Yet Kerala has some of the highest MPCE levels, lowest poverty rates, and best social indicators among all Indian states. They emphasise that the low level of calorie intake in Kerala has little to do with undernutrition, and taking it as a poverty indicator would be highly misleading. There are poorer states, with much higher calorie intake, and much worse nutritional outcomes. So 'Calorie intake and nutrition are simply not the same thing' (Deaton and Dreze, 2010, p. 79).

This is an overkill and misleading too. First, there is nothing new in the argument that calorie 'requirements' vary, depending on individual characteristics, region and time. The calorie (and other nutrient) norms are essentially averages. Second, that the average requirements have gone down because of improvements in the epidemiological environment, less strenuous activity patters, and more sedentary life-styles is also not contentious, though the extent of reduction in calorie requirements remains uncertain. To overcome these difficulties, it is appropriate to link poverty lines to a range of calorie norms instead of abandoning them for the reasons stated. The claim that calorie intake tends to be higher in the 'poorer' states is specious. It is not self-evident that the correlations referred to have any validity in the absence of price and other effects embodied in a demand relation. If food commodities that are major sources of calories are cheaper in poorer states, this may partly explain why calorie intakes are higher in poorer states. Allowing for these price effects, calorie intake and expenditure exhibit a strong positive relationship — the opposite of what the Deaton-Dreze (2010) illustration suggests. If the calorie norm is replaced with an appropriate range, the oddity in the regional poverty patterns may disappear or weaken considerably.

Hence, there is a risk of throwing the baby out with the bathwater by delinking poverty line and calorie (nutritional) norm(s).

\footnotetext{
${ }^{17}$ Deaton and Dreze's (2010) ire is directed against Patnaik’s (2010) “nutrient-invariant poverty lines”. They observe "This method is like anchoring a ship to an iceberg and hoping that, contrary to all reality, we are safely moored to the land" (p. 79).
} 


\section{Poverty Nutrition Trap (PNT)}

The effect of nutritional intake on labour productivity and wage rates, an important area for research for economists and nutritionists, found initial expression in the form of the efficiency wage hypothesis. It postulated that in developing countries, particularly at low levels of nutrition, workers are physically incapable of doing hard manual labour. Hence their productivity is low which then implies that they get low wages, have low purchasing power and, therefore, low levels of nutrition, completing a vicious cycle of deprivation. These workers are unable to save very much so their assets - both physical and human are minimal. This reduces their chances of escaping the poverty-nutrition trap (henceforth PNT). ${ }^{18}$

The extant literature has largely ignored the impact of micronutrient deprivation on labour productivity - including the possibility of the existence of a PNT with respect to micronutrients. Our analysis is based on a nation-wide household survey conducted by the National Council of Applied Economic Research in 1994. ${ }^{19}$ We test for the existence of a PNT in the case of calories and four key micronutrients - carotene, iron, riboflavin, and thiamine - for three categories of wages (sowing, harvesting, and other) and for male and female workers separately.

We conclude that PNT exists in one third (i.e. 10) of the 30 cases. It exists for female harvest wage and female sowing wage for calories. In the case of carotene, male workers engaged in harvesting are subject to the PNT, whereas both male and female workers engaged in harvesting are subject to PNT in the case of iron. In the case of riboflavin female workers engaged in harvesting and sowing and male workers engaged in harvesting are subject to PNT. Since harvesting is physically more demanding than sowing, there is a higher incidence of PNT in harvesting.

Whereas the PNT holds for calories only in the cases of female sowing and female harvesting wages, it holds for males in the case of male harvesting wages (carotene, iron, and riboflavin). For females PNT holds in respect of harvesting and sowing wages for calories, thiamine, and riboflavin, PNT does not exist for females in the case of carotene, and it exists only for harvesting wages in the case of iron. Hence, an analysis which concentrates exclusively on energy intake may present an incomplete picture of the existence of PNT.

\footnotetext{
${ }^{18}$ See Dasgupta and Ray (1986, 1987). Srinivasan (1994) offers a cogent critique.

${ }^{19}$ For details of the survey and methodology for estimating PNT, see Jha et al. (2009).
} 
This analysis shifts the focus to lack of nutritional adequacy as a precondition for participation in labour market activities. Even if some succeed in participating, their wage earnings will not allow them to escape the poverty nutrition trap. Indeed, a mild labour shock (e.g. associated with a crop shortfall) would worsen their plight, as the risk of loss of employment would be considerably higher. In particular, female workers are more prone to PNT than male workers, and there is a persistent gender inequality in rural India. We find that improving nutrient intakes can have significant effects on rural wages and, therefore, on the possibility of breaking PNT as well as reducing poverty. Thus public policy should concentrate urgently on providing direct nutritional supplements to the nutritionally deprived in addition to pursuing direct poverty alleviation policies.

\section{Is Child Undernutrition Underestimated?}

Poverty is multi-dimensional and money-metric indicators such as minimum income or expenditure cannot adequately capture all these dimensions. Attention has therefore shifted to other indicators such as health status, more closely related to basic capabilities of individuals. As Sen $(1985,1999)$ has repeatedly argued, the correspondence between basic capabilities (e.g., to live a healthy and productive life) and level of income is typically weak. It is, therefore, not surprising that welfare indicators including income/expenditure, health and education reflect a diverse pattern in India. While most indicators have continued to improve, social progress has followed diverse patterns, ranging from accelerated progress in some fields to slowdown and even regression in others. Specifically, a composite index of undernutrition of children under five years is about $60 \%$ - or, six out of 10 children are undernourished - tells a grim story of how 'nasty, brutish and short' their lives are, as delineated below.

The most commonly used anthropometric measures are stunting (low height-for-age), wasting (low weight-for-height) and underweight (low weight-for-age). Stunting is an indicator of chronic undernutrition, attributable to prolonged food deprivation, and/or disease or illness; wasting is an indicator of acute undernutrition, caused by more recent food deprivation or illness; underweight is an indicator of both acute and chronic undernutrition. Children whose measurements fall below a certain threshold of the reference population, based on recent WHO standards, are considered undernourished: stunted, wasted or underweight (WHO, 2006 a, b). 
An important feature of these indicators is the overlap between them: some children who are stunted will also be wasting and/or be underweight; those who have wasting will also be stunted or and/or underweight. So there is a need for a more comprehensive measure of child undernutrition. Following the important work of Svedberg (2000, 2007), a new aggregate indicator is constructed that encompasses all undernourished children, be they wasted and/or stunted and /or underweight in Gaiha et al. (2010 d), based on IHDS. This is the composite index of anthropometric failure (CIAF).

Table 8 points to more pervasive anthropometric failure in terms of the CIAF relative to conventional indicators of being underweight, stunted or wasted. The CIAF is about 59\% (or, 6 out of 10 children are undernourished). Among the subcategories, stunting and underweight, and stunting alone account for well over half of the CIAF. Children who fail in all three dimensions (simultaneously wasted, stunted and underweight) account for a non-negligible share (13.5\%). Underweight alone account for the lowest share (about 6\%).

Recent evidence suggests that children suffering from more than one anthropometric failure are more susceptible to infectious diseases (e.g., diarrhea, acute respiratory infection) than those suffering from no failure or just one failure. Worse, these diseases are associated with high risks of child mortality. Our analysis confirms that, except for wasted and underweight and stunted only, in all other cases the prevalence of diarrhea was higher than in the reference group of no failure. In fact, the highest prevalence rate was among children who were simultaneously stunted and underweight, and those who were wasted, underweight and stunted.

\section{Table 8}

Our analysis of determinants of CIAF yields new insights. The larger the number of five-year old children, the greater is the competition for food and health care, and the higher the undernutrition. Maternal education reduces it, as it is linked to better child care and healthier diets. Quality of kitchen — whether it has a vent — contributes to more hygienic living conditions and thus reduces CIAF. Above all, the higher the income, the lower is child undernutrition. Food prices affect child undernutrition significantly as changes in relative prices induce substitutions between food commodities and in nutrient intake. Of particular significance are prices of sugar, eggs and vegetables. While the price of milk is also positively related to undernutrition, the effect is not so robust. Lowering these prices is thus 
likely to contribute significantly to reduction in undernutrition. As food price stabilisation continues to elude policymakers, an option is to ensure better distribution of food through the Integrated Child Development Services (ICDS). Another priority is awareness building for hygienic living while female literacy grows. Although NREGS has contributed to livelihood expansion, problems abound in targeting the poorest. Thus, a wide range of interventions is necessary that transcend income growth acceleration to ameliorate child undernutrition.

\section{Double Burden of Undernutrition and Obesity}

While the relentless battle against poverty and hunger continues, the double burden of undernutrition and obesity, a new phenomenon particularly in middle income developing countries, that afflicts millions has barely received careful attention. Underweight children and obese adults are two manifestations of this scourge.

Among children in developing countries underweight is more prevalent than overweight. This is prevalent among Indian children. Among adults, on the other hand, obesity has shot up in a few years.

The emergence of the double burden is symptomatic of the dietary transition underway in developing countries as a result of growing prosperity and urbanization. Diets are shifting from traditional foods towards low-cost energy-dense foods, and physical activity patterns are becoming less strenuous and more sedentary. The excess energy from these foods may affect children and adults within the same household differently. Children may use up the excess energy and still remain underweight while adults are more likely to gain weight. Intrahousehold food allocation biases between adults and children, and between males and females, compound these effects.

Based on India Human Development Survey (IHDS, 2005), we conclude the following about the prevalence of the double burden and related aspects ${ }^{20}$.

Of the under-five children, $41.50 \%$ were underweight; about $22 \%$ were wasted; and about $36 \%$ were stunted. In rural areas and urban slums, $43.50 \%$ of children were underweight, compared with $32.5 \%$ in the urban areas. In urban slums, the proportion of wasted children was the highest (about 26\%), followed by the rural areas (22\%), and, then, urban (just under $21 \%)$.

${ }^{20}$ For details, see Gaiha et al. (2010 e). 
Rural areas were the worst in terms of stunting (about 38\%), followed by urban slums (about $35 \%$ ), and then urban areas (just under 30\%).

In the age group $2-11$ years, $4.96 \%$ of the children were obese. ${ }^{21}$ The obesity rate was highest in urban areas (6.55\%), followed by the rural (4.57\%), and then urban slums (about 3.5\%).

Disaggregation into poor and non-poor households suggests that obesity was nearly as prevalent among the former (just under 5\%) as among the latter (just over 5\%). So obesity prevails despite economic deprivation.

About $16 \%$ of adults were overweight or obese. Adults from economically deprived households were half as likely to be overweight than others (about $7 \%$ as compared with $14.18 \%$ ), but one-third as likely to be obese (about $1.25 \%$ as against $3.75 \%$ ).

The rural-urban variation is striking. In urban areas, the proportion of the overweight was the highest (just under 22\%), followed by urban slums (over 14\%), and then rural areas (about 9\%). The obesity rate was highest in urban areas (under 7\%), slightly lower in urban slums (about 5.50\%) and considerably lower in rural areas (under 2\%).

We now consider the subset of households that contain both underweight children (under-five) and obese adults. Although their share was low — about 3.30\% in the aggregate sample — it varied slightly between the poor and non-poor (2.35\% and 3.75\%, respectively). In a more disaggregated MPCE classification (Rs <300, Rs 300-500, Rs 500-1000 and > Rs 1000), there was, however, clear progression, with the obesity rate rising from $2.85 \%$ to $6.50 \%$. In urban areas and urban slums the rate (about 4.86\%) was almost twice as high as in rural areas (2.75\%).

The upsurge in the numbers of the overweight and obese portends higher risks of chronic NCDs. The burden of chronic diseases has risen sharply in India, accounting for $53 \%$ of all deaths and $44 \%$ of disability-adjusted life years in 2005. Worse, many of these deaths occur at early ages and the number of potentially productive years lost due to deaths from cardiovascular disease in the age group of 35-64 (9.2 million years lost in 2000) is the highest in the world. By 2030, it is expected to touch 17.9 million years.

\footnotetext{
${ }^{21}$ We classify children whose BMI $\left(\mathrm{kg} / \mathrm{m}^{2}\right)$ exceeds the $95^{\text {th }}$ percentile value as obese; adults whose BMI is equal to or greater than 25 as overweight; and those with BMI equal to or greater than 30 as obese.
} 
Hence, while growing prosperity and associated life-style and dietary changes are irreversible, a pessimistic reading of the rising burden of diet-related NCDs must be avoided. Although the health policy challenge remains - arising from the conflict between policies that reduce undernutrition and those designed to curb obesity - there is now better awareness of interventions that reduce both. These include promoting breast-feeding, improving the nutritional status of women of reproductive age, and reducing fetal growth retardation. Moreover, their costs are a fraction of treating the much larger numbers likely to suffer from chronic ailments in the near future.

\section{NREG, PDS \& Nutritional Deprivation}

With spiralling food price inflation and sluggish employment growth in both rural and urban areas, the spectre of hunger and nutritional deprivation looms large for millions of households. While the battle lines are sharply drawn between those who pin their hopes of a rapid growth acceleration through a continuing bold fiscal stimulus and others screaming for an early exit before growth prospects are swallowed up by galloping inflation, those most vulnerable to food inflation are sidelined, if not altogether ignored, in the debates on macro stability and growth .Our analysis (Jha et al. 2010), based on primary data collected in Rajasthan, Maharashtra and Andhra Pradesh (henceforth AP) during 2007-08, highlights the extent and severity of nutritional deprivation, and the existing and potential contributions that NREG and PDS can make towards mitigating it.

We first consider the nutritional profiles of these three states, taking into account consumption of calories, proteins, and micronutrients (calcium, iron, carotene, thiamine, riboflavin, Vitamin C and niacin). Using standard cut-off points for each, it turns out that not a single household in AP was adequately nourished in all nine nutrients. Mean consumption of all nutrients except iron was below the respective cut-off point for nutritional adequacy. However, there was considerable inequality in nutrient consumption across the sample with the minimum cut-off for calories, for example, attained only by households in the top $10 \%$ by calorie consumption.

The nutritional profile of Maharashtra is slightly better - $1.3 \%$ of the households were adequately nourished in all nutrients. As in AP, there was considerable inequality in nutritional attainment with the minimum calorie norm reached only by the top $5 \%$ of households for calorie consumption. In Rajasthan, barely $0.5 \%$ of the households were 
adequately nourished across all nine nutrients. However, it had the lowest prevalence of deprivation across all nutrients (29\% of households). But just the top $12 \%$ of households in calorie consumption crossed the minimum norm.

Our results point to varied effects of NREG and PDS on the intake of various nutrients. Both NREG and PDS significantly increased the intake of calories, proteins, iron, among others, in these states. In the case of calcium, however, in Maharashtra, both PDS and NREG had positive and significant effects whereas neither was significant in Rajasthan. In AP, on the other hand, only PDS had a significant effect on calcium consumption. These differences reflect the different ways in which the income from NREG and income transfer implicit in the PDS are spent and the dietary preferences of households in these states.

Using participation measures in PDS and NREG, their effects on nutrient intake are compared $^{22}$. In AP, in most cases, PDS had a larger effect than NREG. By contrast, in Maharashtra, NREG had larger effects in most cases. Rajasthan presents a more complex picture. For some nutrients (e.g. calories, iron and niacin) PDS has larger effects than NREG while for others (e.g. protein, riboflavin) the latter has larger effects. So a general inference about the greater effectiveness of PDS or NREG is ruled out. Further, the effects of NREG wages on nutrient intake in many cases (e.g. protein, calories, niacin) are larger than those of non-NREG income. This is not surprising as physically demanding tasks necessitate higher nutrient intake. This is of course not an issue in the context of real income transfer implicit in the PDS. An implication of these findings is, however, worth emphasising. Unconditional cash transfers touted to avoid administrative costs and corruption involved in the NREG and PDS are likely to be much less effective if the objective is to enable large segments of the rural population to break out of NPT.

\section{Does a Right to Food Matter?}

Prior to the 2009 general elections, the Indian National Congress promised 25 kilograms of food grain per month, at three rupees per kilogram, to every poor family in India (Khera, 2010). The proposed Food Security Bill seeks to deliver on this promise. ${ }^{23}$

\footnotetext{
${ }^{22}$ The effects on nutrient intake are contingent upon a modest real income transfer (Rs 100 per month or a day's NREG wage). For details, see Jha et al. (2010).

${ }^{23}$ Reports in the media vary from elation for to deep skepticism of broadening and universalisation of food entitlements by the National Advisory Council under the leadership of Sonia Gandhi, as part of a campaign to put in place a comprehensive RTF. As emphasized by Khera (2010), the RTF goes beyond the provision of subsidized cereals to ensuring freedom from hunger, malnutrition and other deprivations associated with lack of food.
} 
There are strong advocates of a Right to Food (RTF) Act, given pervasive hunger and child malnutrition. Besides, there are legal compulsions. Article 21 (the fundamental 'right to life') of the Indian Constitution encompasses the right to food while Article 47 of the Directive Principles directs the state to 'regard the raising of the level of nutrition and the standard of living of its people...as among its primary duties', and India being a signatory to various international treaties on these issues. Finally, the Supreme Court has issued several orders on fulfilment of food entitlements (Khera, 2010).

We offer a perspective on the RTF that differs from the vast literature that has emerged around it in recent years ${ }^{24}$.

The RTF as an enforceable claim to a minimum quantity of food of a certain quality carries with it correlated duties, particularly of the state ${ }^{25}$. These include the duty to avoid loss of the means of subsistence, and to provide for the subsistence of those unable to provide for their own (Shue, 1980). Much, of course, will depend on the specific form of the right to food, the corresponding duties/obligations and the implementation mechanisms.

In practical terms, RTF translates into food entitlements, that is, enforceable claims on the delivery of food. These entitlements could be based on trade, production and employment.

Since RTF does not involve state provision of food except under special circumstances of failures of duties to avoid and protect, and natural disasters, in an important sense it could be viewed as a right to policies (or, as 'a right to a right') that enables individuals to produce or acquire minimum food requirements (Osmani, 1999). This may yield useful insights into whether non-fulfilment of the right to food is due to insufficiency of public resources or due to policies followed or both.

From this perspective, recent debates on the National Food Security Bill have concentrated on a rigid interpretation of the RTF as being confined mostly to state provision of food. A quotation from The Hindustan Times ( $5^{\text {th }}$ October, 2010) illustrates: 'The food ministry has rejected both proposals of the National Advisory Council (NAC) on food security. It said the government risked running up against supply constraints and taking on an unsustainable fiscal burden if the proposals were implemented. The rejection means both NAC — headed

\footnotetext{
24 This draws upon Gaiha (2003) and our more recent research on related issues.

${ }^{25}$ For an elaboration, see Gaiha (2003).
} 
by Congress chief Sonia Gandhi — and the government will have to come up with a fresh alternative.’

One NAC proposal had called for introduction of a universal PDS - initially only for the 150 poorest districts - that would offer $35 \mathrm{~kg}$ rice/wheat at Rs 3 for $80 \%$ of the families in rural areas and 33\% in urban areas. The second sought to extend the benefit across the country to $42 \%$ of rural families and 33\% of urban families and provide $25 \mathrm{~kg}$ of rice/wheat at either Rs 5 or Rs 7.50 per kg to above poverty line (APL) families in rural areas; urban APL households would be excluded.

NAC estimated that grain requirement for the first option would be 70.4 million tonnes (mt) and for the second $70 \mathrm{mt}$. The associated subsidy would be Rs 90,264 crore in the first instance and Rs 85,156 crore (at an issue price of Rs 5) and Rs 79,181 crore (at an issue price of Rs 7.50), it said' (The Hindustan Times, 'Ministry Rejects NAC's Food Security Proposal').

Although estimates of the subsidy involved differ, it is likely that the fiscal burden will be unsustainable. More importantly, given the waste involved (it takes Rs 6 of PDS expenditure to transfer a rupee of real income), it is not even clear if this is the best way of fulfilling RTF. If, instead, more sensible policies are pursued that aim to augment low productivity in agriculture, avoid market imperfections that come in the way of remunerative farm gate food prices, and expand livelihood options, fulfilment of food entitlements may be far less costly. In fact, an analysis with $61^{\text {st }}$ round of the NSS yields two robust insights: the higher the agricultural wage rate, the lower is the demand for rural public works; and the lower the food price, the lower is the demand for subsidized food (Gaiha et al.2009). A crucial requirement is a clear enunciation of time-bound objectives and a coherent policy framework. Although not specific to the right to food, what really matters is the effective use of resources in enforcement. As experience accumulates-both juridical and policy related-these costs may decline substantially (Gaiha, 2003).

Hence, contrary to assertions that RTF is both 'undefinable' and 'undeliverable', it was argued that it is evolving slowly into an enforceable right. Some of the arguments against it are exaggerated, if not mistaken. More significantly, its potential for enabling governments to do what they should by providing a strong foundation for their poverty alleviation programmes and policies, and for sharpening the focus of CSOs as active agents in such 
programmes is substantial. While realization of this right is likely to be slow, difficult and uncertain, it would be a mistake to discard it on the ground that 'too many rights may well make a wrong' (The Economist, 2001, p. 20).

\section{Concluding Observations}

This chapter focused on dietary changes, their nutritional implications, and the policy response to alleviate nutritional deprivation.

The downward shifts in the calorie and protein intakes over the period 1993-2004 were associated with changes in diets. A demand-based explanation is offered in which higher food prices and near stagnant expenditure/income in rural India played significant roles, while allowing for lower calorie 'requirements' due to less strenuous activity patterns, life-style changes and improvements in the epidemiological environment.

In elaborating dietary transition in India, we reviewed recent evidence on eating out, emphasizing that it is more pervasive than a middle-class urban phenomenon.

We then examined the relationship between calorie deprivation and poverty, and argued against delinking of the two. Manifestations of undernutrition imply serious welfare implications not just in the present but also in the longer-term. PNT, for example, is a vicious circle in which at low levels of nutrition, productivity is low, wages are low, purchasing power is low and, consequently, there is low nutrition.

A new measure of child undernutrition, more comprehensive than conventional ones, points to much higher levels of undernutrition (6 out of 10 are undernourished) and higher risks of infectious diseases. The double burden of undernutrition and obesity exacerbates the gravity of malnutrition. As diets shift from traditional foods towards low-cost energy-dense foods, and physical activity patterns become less strenuous and sedentary, the excess energy from these foods affects children and adults differently within the same household. Children use up the energy and still remain underweight while adults gain weight and become obese. A consequence is a rise in the risk of chronic non-communicable diseases.

Although a wide range of interventions is called for, we concentrated on the (potential) contribution of NREG and PDS towards mitigating undernutrition (including micronutrient deficiency). Their nutritional effects varied across states and programmes. So a general 
inference about the greater effectiveness of PDS or NREG is ruled out. However, nutritional outcomes contingent upon a modest transfer of real income is substantial. So it is not really a question of larger allocations to the PDS and NREG but one of making sure that the transfers intended for the poor reach them.

As current debates on food security have veered towards RTF, a new perspective is delineated in which it is viewed as a right to policies (or, as a right to a right) designed to ensure fulfilment of food entitlements. Whether it will make a difference to the lives of the poor will depend largely on how it is conceptualised and implemented.

\section{References}

Atkinson, A.B. (1987), 'On the Measurement of Poverty’, Econometrica, 55(4), 749-64.

Dasgupta, P. and D. Ray (1986) 'Inequality as a Determinant of Malnutrition and Unemployment: Theory’, Economic Journal, 96, 1011-1034.

Dasgupta, P. and D. Ray (1987) 'Inequality as a Determinant of Malnutrition and Unemployment: Policy’, Economic Journal, 97, 177-188.

Datt, G., and M. Ravallion (2009) 'Shining for the Poor Too?’, Economic and Political Weekly,. XLV (7), 55-60

Deaton, A. and J. Dreze (2009), 'Food and Nutrition in India: Facts and Interpretations', Economic and Political Weekly, XLIV (7), 42-65.

Deaton, A. and J. Dreze (2010), 'Nutrition, Poverty and Calorie Fundamentalism: Response to Utsa Patnaik', Economic and Political Weekly,.XLV (14), 78-80.

Deolalikar, A. (2010), 'The Middle Class in Asia: Emerging Trends and Patterns and Their Implications', paper presented at a Workshop on the Asian Middle Class, Asian development Bank, May 27-28.

Gaiha, R. (2003) 'Does the Right to Food Matter?’ Economic and Political Weekly, October 4.

Gaiha, R., Vani. S. Kulkarni, G. Thapa and K. Imai (2009) 'Wages, Prices and Anti-Poverty Interventions in Rural India', submitted for publication.

Gaiha, R., R. Jha and Vani S. Kulkarni (2010a), 'Prices, Expenditure and Nutrition in India', Australia South Asia Research Centre, Australian National University, Working Paper No.2010/15.

Gaiha, R., R. Jha and Vani S. Kulkarni (2010b), 'Demand for Nutrients in India, 1993-2004', Australia South Asia Research Centre, Australian National University, Working Paper No.2010/16

Gaiha, R., R. Jha and Vani S. Kulkarni (2010c), 'How Pervasive is Eating Out in India?', Australia South Asia Research Centre, Australian National University, Working Paper No.2010/16 (Revised and forthcoming in Journal of Asian and African Studies).

Gaiha, R., R. Jha and Vani S. Kulkarni (2010d), 'Child Undernutrition in India’, Australia South Asia Research Centre, Australian National University, Working Paper No.2010/11. 
Gaiha, R., R. Jha and Vani S. Kulkarni (2010e), 'Obesity, Affluence and Urbanisation in India', ASARC Working Paper 2010/10, Canberra: ANU.

Gopalan, C., B. Sastri, and S. Balasubramanian (1971), Nutritive Value of Indian Foods, National institute of Nutrition: Indian Council of Medical Research: Hyderabad.

Indian Council of Medical Research (1990), Nutrient Requirements and Recommended Dietary Allowances for Indians, New Delhi: ICMR.

Jha, R., R..Gaiha and A. Sharma (2009), 'Calorie and Micronutrient and Poverty Nutrition Traps in Rural India’, World Development, 37(5), 982-91.

Jha, R., S. Bhattacharya and R. Gaiha (2010), 'Social Safety Nets and Nutrient Deprivation: An Analysis of the National Rural Employment Guarantee Programme and the Public Distribution System in India', ASARC Working Paper 2010/04, Australian National University.

Khera, R. (2010) 'India’s Right to Food Act: Beyond the Rhetoric’, India in Transition, 7 July.

Kulkarni, Vani. S. and R. Gaiha (2010), 'Dietary Transition in India', Philadelphia: India in Transition, CASI, University of Pennsylvania, March.

Osmani, S. (1999) ‘Human Rights to Food, Health and Education’, draft.

Patnaik, U. (2010) 'A Critical Look at Some Propositions on Consumption and Poverty', Economic and Political Weekly, 6 February.

Pingali, P. and Y. Khwaja (2004), 'Globalisation of Indian Diets and the Transformation of Food Supply Systems’, ESA Working Paper No. 04-05, Rome: FAO.

Ravallion, M. (1989), 'Is Undernutrition Responsive to Changes in Income?’, WPS 303, Washington DC: The World Bank.

Sen, Amartya (1985), Commodities and Capabilities, Amsterdam: North Holland.

Sen, Amartya (1999), Development as Freedom, New York: Knopf.

Shue, H. (1980) Basic Rights, NJ: Princeton University Press.

Srinivasan, T.N., (1992), 'Undernutrition: Concepts, Measurements and Policy Implications', in: S.R. Osmani (ed.), Nutrition and Poverty, Clarendon Press,

Srinivasan, T.N., (1994), 'Destitution: A Discourse', Journal of Economic Literature, 32, 1842-1855.

Svedberg, P. (2000), Poverty and Undernutrition: Theory, Measurement, and Policy, Oxford: Oxford University Press.

Svedberg, P. (2007), 'Taking Action for the World's Poor and Hungry People', Speaker Summary Note, Beijing, China, October 17-19 (mimeo).

The Economist (2001) 'Righting Wrongs', August 18.

The Hindustan Rimes (2010) 'Ministry Rejects NAC’s Food Security Proposals', $5^{\text {th }}$ October.

WHO (2006), 'Obesity and Overweight', Fact Sheet no. 311, September.

WHO (2006), WHO Child Growth Standards: Length/Height for Age, Weight for Age, Weight for Length, Weight for Height, Available at http://www.ncbi.nlm.nih.gov/pubmed/16817681 
Table 1

Calorie Intake Distributions in Rural India, 1993-2004 ${ }^{26}$

\begin{tabular}{|c|c|c|c|c|c|}
\hline \multirow{2}{*}{ Year } & \multicolumn{4}{|c|}{ Range of Calorie Intake Per Capita Per Day } & \multirow{2}{*}{ Total } \\
\cline { 2 - 5 } & $<1800$ & $1801-2400$ & $2401-3000$ & $>3000$ & \\
\hline \multirow{2}{*}{1993} & 31.09 & 40.07 & 19.42 & 9.42 & 100 \\
& $(1491)$ & $(2084)$ & $(2650)$ & $(3636)$ & $(2156)$ \\
\hline \multirow{2}{*}{2004} & 36.68 & 43.11 & 15.07 & 5.14 & 100 \\
& $(1516)$ & $(2071)$ & $(2629)$ & $(3925)$ & $(2047)$ \\
\hline
\end{tabular}

Table 2

Calorie Intake Distributions in Urban India, 1993-2004

\begin{tabular}{|c|c|c|c|c|c|}
\hline \multirow{2}{*}{ Year } & \multicolumn{4}{|c|}{ Range of Calorie Intake Per Capita Per Day } & \multirow{2}{*}{ Total } \\
\cline { 2 - 5 } & $<1700$ & $1701-2100$ & $2101-2600$ & $>2600$ & \\
\hline \multirow{3}{*}{1993} & $\begin{array}{c}28.12 \\
(1426)\end{array}$ & $\begin{array}{c}29.62 \\
(1900)\end{array}$ & $\begin{array}{c}25.76 \\
(2320)\end{array}$ & $\begin{array}{c}16.49 \\
(3107)\end{array}$ & $\begin{array}{c}100 \\
(2074)\end{array}$ \\
\hline \multirow{2}{*}{2004} & 29.40 & $\begin{array}{c}34.52 \\
(1900)\end{array}$ & $\begin{array}{c}24.67 \\
(2313)\end{array}$ & $\begin{array}{c}11.41 \\
(3252)\end{array}$ & $\begin{array}{c}100 \\
(2021)\end{array}$ \\
\hline
\end{tabular}

Table 3

Protein Intake Distributions in Rural India, 1993-2004

\begin{tabular}{|c|c|c|c|c|c|}
\hline \multirow{2}{*}{ Year } & \multicolumn{3}{|c|}{ Range of Protein Intake Per Capita Per Day (Gms) } & \multirow{2}{*}{ Total } \\
\cline { 2 - 5 } & $<45$ & $46-60$ & $61-75$ & $>75$ & \\
\hline \multirow{2}{*}{1993} & 23.81 & 33.79 & 22.79 & 19.61 & 100 \\
& $(37.1)$ & $(52.4)$ & $(66.8)$ & $(94.4)$ & $(60.3)$ \\
\hline \multirow{2}{*}{2004} & 28.81 & 38.05 & 21.46 & 11.68 & 100 \\
& $(37.4)$ & $(52.2)$ & $(66.3)$ & $(93.9)$ & $(55.8)$ \\
\hline
\end{tabular}

Table 4

Protein Intake Distributions in Urban India, 1993-2004

\begin{tabular}{|c|c|c|c|c|c|}
\hline \multirow{2}{*}{ Year } & \multicolumn{3}{|c|}{ Range of Protein Intake Per Capita Per Day (Gms) } & \multirow{2}{*}{ Total } \\
\cline { 2 - 5 } & $<45$ & $46-60$ & $61-75$ & $>75$ & \\
\hline \multirow{2}{*}{1993} & 24.90 & 37.77 & 23.11 & 14.23 & 100 \\
& $(37.1)$ & $(52.4)$ & $(66.5)$ & $(90.7)$ & $(57.3)$ \\
\hline \multirow{2}{*}{2004} & 29.40 & 34.50 & 24.69 & 11.40 & 100 \\
& $(37.8)$ & $(52.3)$ & $(66.2)$ & $(94.9)$ & $(55.4)$ \\
\hline
\end{tabular}

${ }^{26}$ Tables 1 to 7 are from Gaiha et al. (2010 a). 
Table 5

Fat Intake Distributions in Rural India, 1993-2004

\begin{tabular}{|c|c|c|c|c|c|}
\hline \multirow{2}{*}{ Year } & \multicolumn{4}{|c|}{ Range of Fat Intake Per Capita Per Day (Gms) } & \multirow{2}{*}{ Total } \\
\cline { 2 - 5 } & $<20$ & $21-30$ & $31-50$ & $>50$ & \\
\hline \multirow{2}{*}{1993} & 34.30 & 25.08 & 26.09 & 14.54 & 100 \\
& $(14.0)$ & $(24.7)$ & $(38.3)$ & $(72.1)$ & $(31.5)$ \\
\hline \multirow{2}{*}{2004} & 22.59 & 27.21 & 33.58 & 16.62 & 100 \\
& $(15.0)$ & $(24.9)$ & $(38.3)$ & $(74.6)$ & $(35.4)$ \\
\hline
\end{tabular}

Table 6

Fat Intake Distributions in Urban India, 1993-2004

\begin{tabular}{|c|c|c|c|c|c|}
\hline \multirow{2}{*}{ Year } & \multicolumn{4}{|c|}{ Range of Fat Intake Per Capita Per Day (Gms) } & \multirow{2}{*}{ Total } \\
\cline { 2 - 5 } & $<25$ & $26-40$ & $41-60$ & $>60$ & \\
\hline \multirow{2}{*}{1993} & 25.04 & 29.84 & 26.15 & 18.97 & 100 \\
& $(18.2)$ & $(32.3)$ & $(48.6)$ & $(80.2)$ & $(42.1)$ \\
\hline \multirow{2}{*}{2004} & 15.39 & 31.02 & 31.56 & 22.04 & 100 \\
& $(19.4)$ & $(32.6)$ & $(48.9)$ & $(85.8)$ & $(47.4)$ \\
\hline
\end{tabular}

Table 7

Mean Per Capita Consumption of Food Commodities (Gms), 1993 and 2004

\begin{tabular}{|c|c|c|c|c|c|c|c|c|c|}
\hline $\begin{array}{c}\text { Rural/Urban } \\
\text { Year }\end{array}$ & Cereals & $\begin{array}{c}\text { Milk Products } \\
\text { Ghee/Butter }\end{array}$ & $\begin{array}{c}\text { Vanaspati- } \\
\text { Oil }\end{array}$ & Sugar & Eggs & $\begin{array}{c}\text { Meat/Fish } \\
\text { /Poultry }\end{array}$ & $\begin{array}{c}\text { Pulses/Nuts } \\
\text { /Dry Fruits }\end{array}$ & Fruits & Vegetables \\
\hline Rural & & & & & & & & & \\
\hline 1993 & 448 & 114.3 & 12.3 & 26 & 1.2 & 10.4 & 366.3 & 16.4 & 159.5 \\
\hline 2004 & 403.9 & 111.8 & 16.2 & 24.7 & 1.9 & 11.3 & 203.5 & 19.7 & 167.6 \\
\hline Urban & & & & & & & & & \\
\hline 1993 & 355.2 & 143.2 & 18.6 & 32.4 & 2.9 & 13.9 & 523.7 & 32.4 & 168.1 \\
\hline 2004 & 331.3 & 149.1 & 22.1 & 29 & 3.3 & 14.2 & 327.2 & 33.1 & 182.4 \\
\hline
\end{tabular}

Table 8

Subgroups of Child Undernutrition and CIAF in 2004-05

\begin{tabular}{|l|c|}
\hline Groups & Share of Under 5 Children (\%) \\
\hline 1.No Failure & 41.36 \\
\hline 2.Wasting Only & 6.86 \\
\hline 3.Wasting and Underweight & 9.41 \\
\hline 4.Wasting, Stunting and Underweight & 7.92 \\
\hline 5.Stunting and Underweight & 19.80 \\
\hline 6.Stunting Only & 11.08 \\
\hline 7.Underweight Only & 3.57 \\
\hline CIAF (=2+3+4+5+6+7) & 58.64 \\
\hline Source: Gaiha, Jha and Kulkarni (2010c). \\
\hline
\end{tabular}


Figure 1: Calorie Engel Curves in Rural India, 1993 and 2004

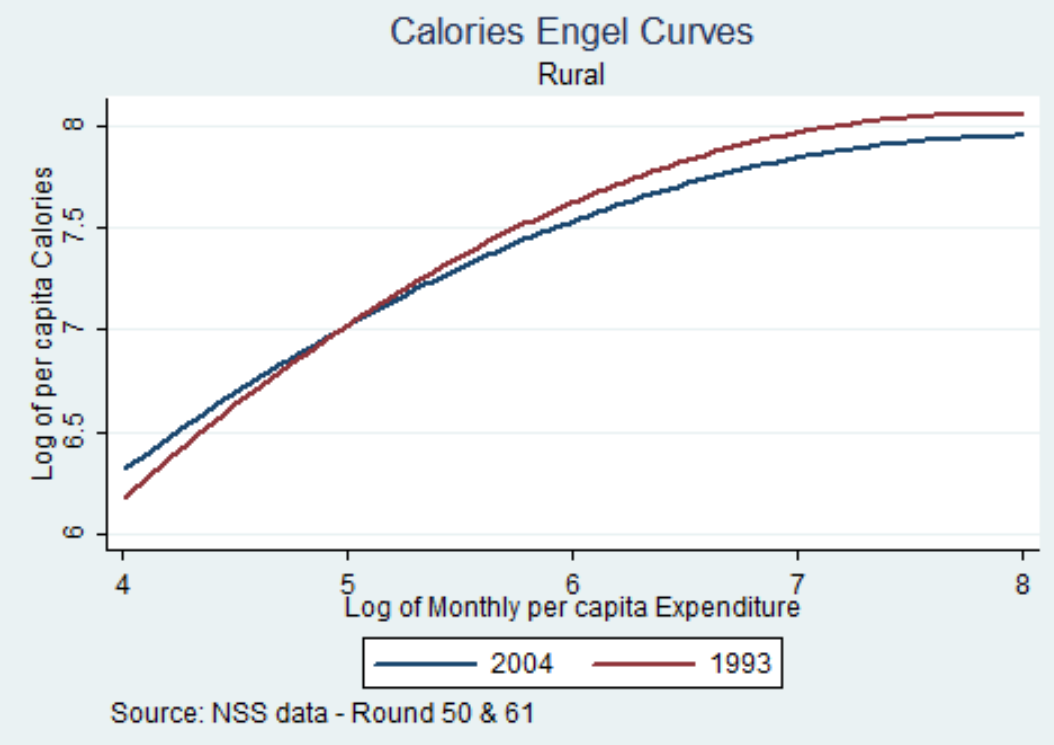

Figure 2: Calorie Engel Curves in Urban India, 1993 and 2004

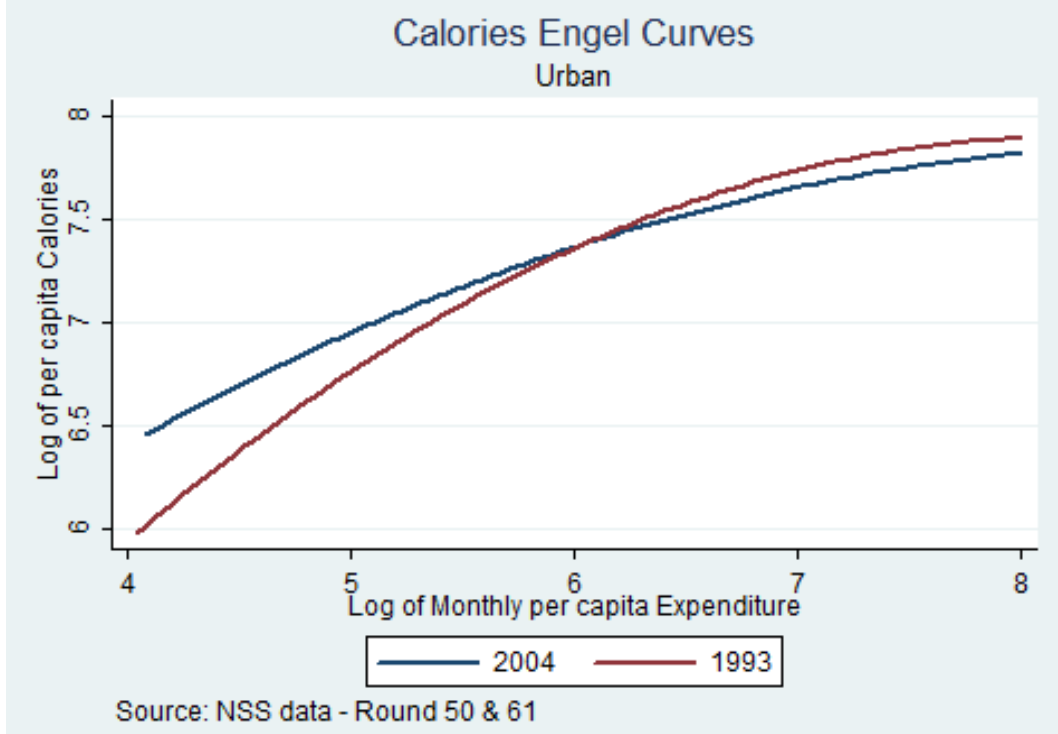


Figure 3: Protein Engel Curves in Rural India, 1993 and 2004

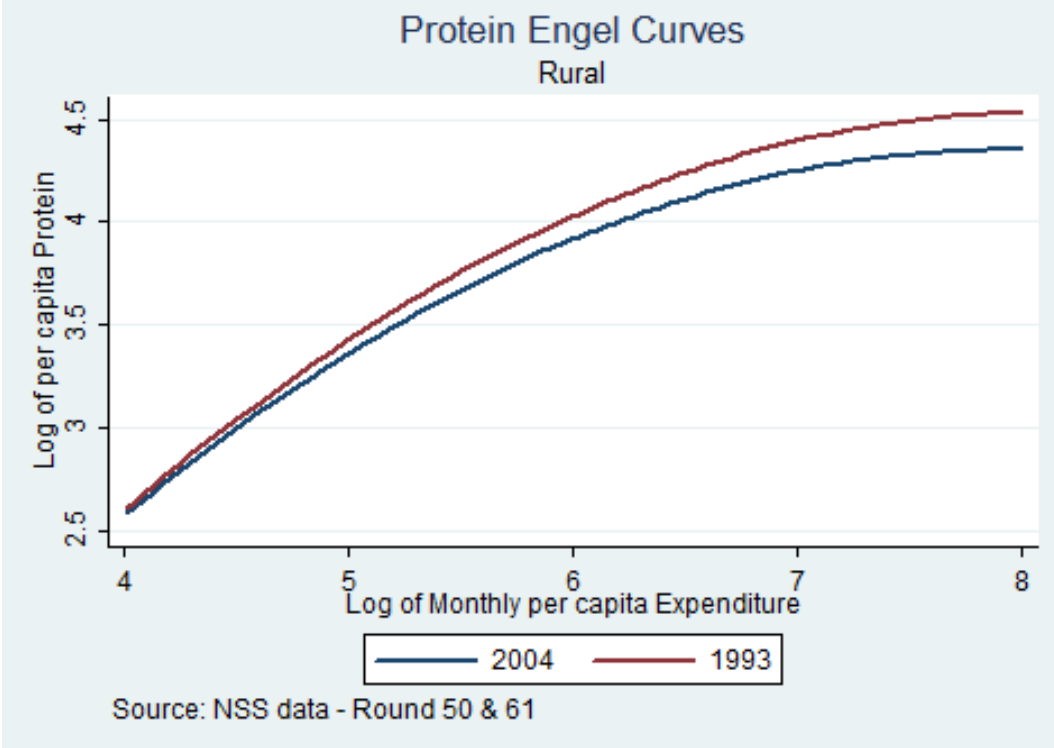

Figure 4: Protein Engel Curves in Urban India, 1993 and 2004

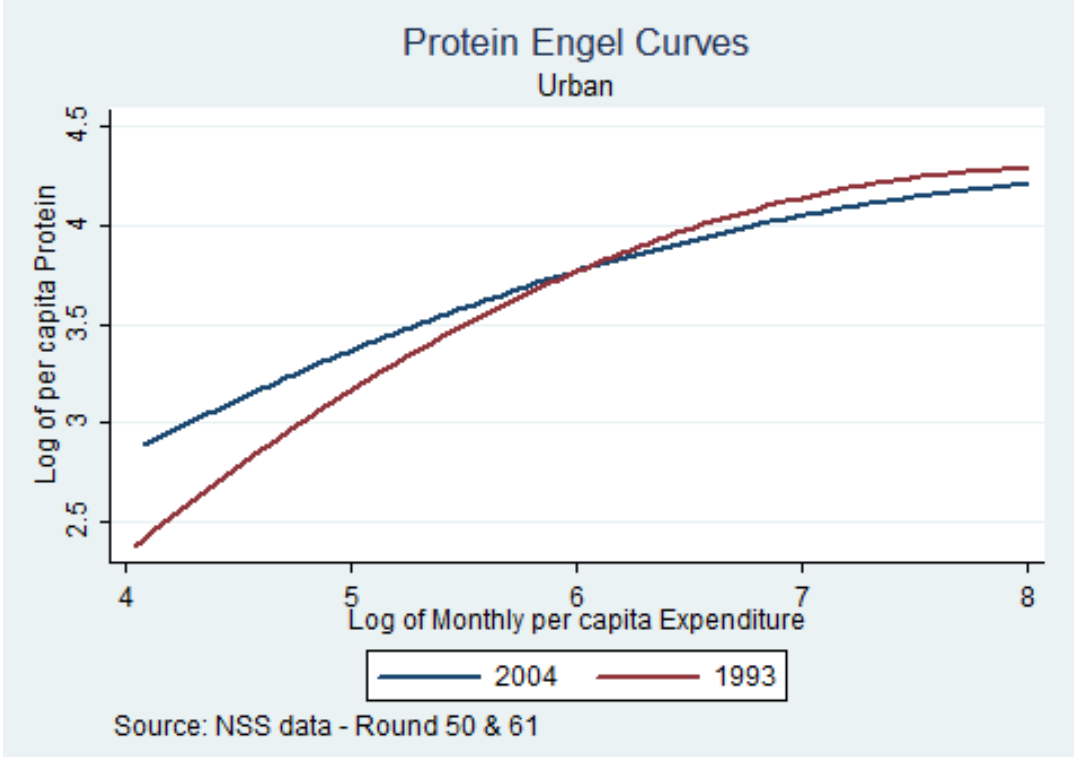


Figure 5: Fat Engel Curves in Rural India, 1993 and 2004

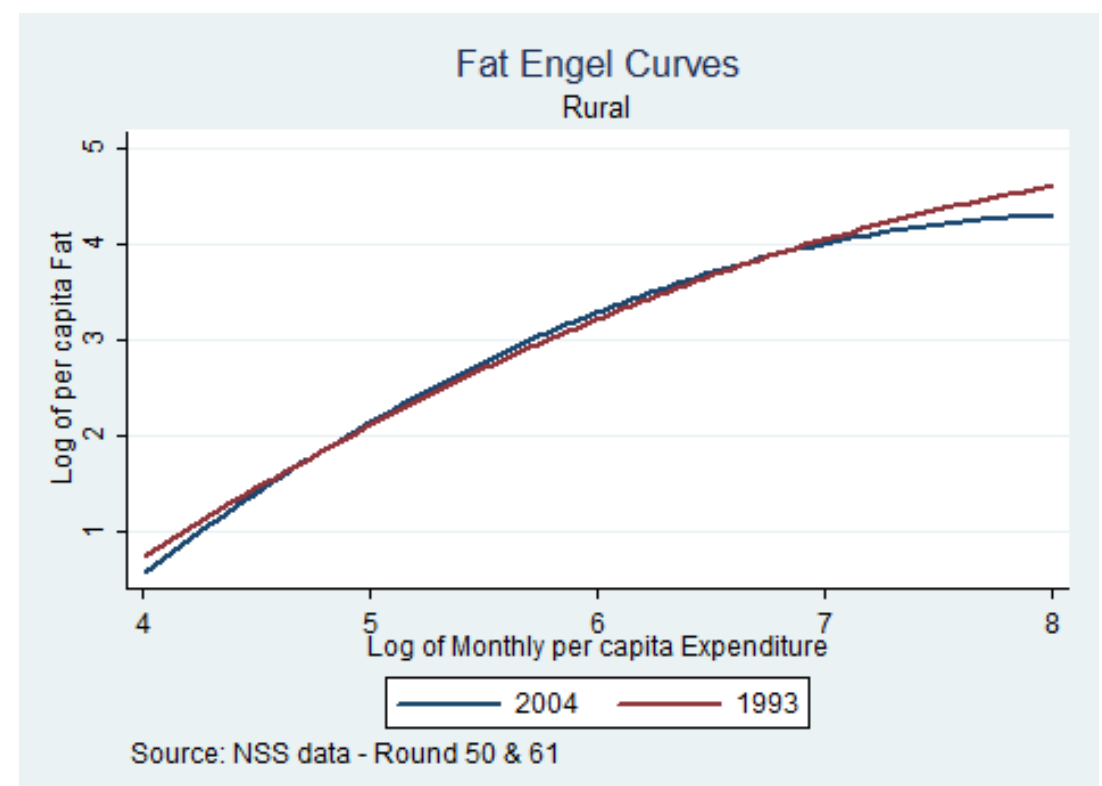

Figure 6: Fat Engel Curves in Urban India, 1993 and 2004

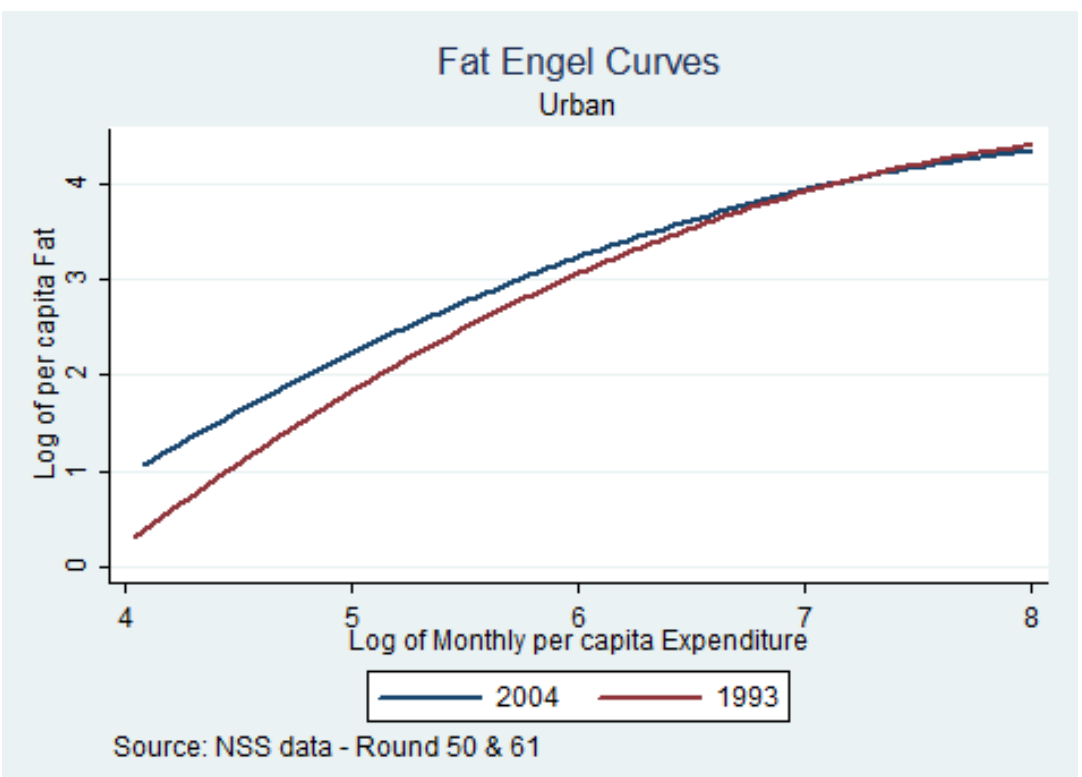

